Volume and Issues Obtainable at Center for Sustainability Research and Consultancy

Journal of Accounting and Finance in Emerging Economies

ISSN: 2519-0318 \& ISSN (E): 2518-8488

Volume 7: Issue 3 September 2021

Journal homepage: www.publishing.globalcsrc.org/jafee

\title{
Mediating Role of Job Embeddedness between Interruptions at Work and Job Satisfaction of Gritty Faculty Members
}

Quaisar Ijaz Khan, Assistant Professor, College of Commerce, Government College University

Faisalabad, Pakistan

Raheel Mumtaz, Assistant Professor, College of Commerce, Government College University

Faisalabad, Pakistan

*Muhammad Farooq Rehan, Assistant Professor, College of Commerce, Government College

University Faisalabad, Pakistan

Sumera Ilyas, M.Phil. Scholar at College of Commerce, Government College University

Faisalabad, Pakistan

*Corresponding author's email: farooq.rehan@gcuf.edu.pk

\begin{tabular}{l}
\hline ARTICLE DETAILS \\
History \\
Revised format: Aug 2021 \\
Available Online: Sep 2021 \\
\hline Keywords \\
Trade Openness, CO2 \\
Emission, Human Capital, \\
Services Sector Value \\
Addition, Developing \\
Countries
\end{tabular}

JEL Classification

$M 1, M 2$

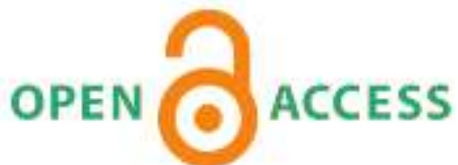

\section{ABSTRACT}

Purpose: The study has examined the job satisfaction of gritty faculty members working on Basic Pay Scale, in public sector universities of Pakistan. The construct is derived from motivational intensity theory in the context of Islamic Republic of Pakistan.

Design/methodology/approach: A total of 289 gritty faculty members from Islamic Republic of Pakistan's Public Sector Universities participated in this study by filling survey questionnaire. The survey questionnaire was adopted from different sources and tested for validity and reliability.

Findings: The study found that interruptions at work have significantly positive relationship with job embeddedness and job satisfaction and most importantly the unique concept for mediating relationship of job embeddedness between interruptions at work and job satisfaction has been established in this study. The study further examined and found that selfefficacy, multitasking, social astuteness has significantly positive relationship with job satisfaction.

Research limitations/implications: The application of the results requires intensive care for other universities and type of appointments in public and private universities of Pakistan and other countries of the world.

Practical implications: The universities in public sector are required to define the job statues and flexible working hours for the faculty members working on basic pay scale to enhance the job satisfaction of faculty members.

(C) 2021, The authors, under a Creative Commons AttributionNonCommercial 4.0 
Recommended citation: Khan, Q. I., Mumtaz, R., Rehan, M. F. and Ilyas, S. (2021). The Mediating Role of Job Embeddedness between Interruptions at Work and Job Satisfaction of Gritty Faculty Members. Journal of Accounting and Finance in Emerging Economies, 7 (3), 799 811.

\section{Introduction}

Islam instructs upon its believers to acquire knowledge and employ it to produce more knowledge and wisdom. Man is made vicegerent of Allah Almighty on the earth just for the reason that he has wisdom and knowledge. Man is supreme over all creatures; said in Holy Quran (2:30-33), When the Angels quizzed Adam's appropriateness for representation: Allah mentioned Adam 's knowledge to persuade them (Khalid, Chaudhry, \& Ilyas, 2014). The ergonomics at workplace is attracting the interest of researchers now a days. The concept is not the new however gaining noticeable attention currently. Ergonomic is not concerned only with seating, car design, instruments, and controls. Its something different from that and it is a process of continuously designing, managing, or arranging workplaces, systems, and products in such a way that they become fit and flexible for employees who use them (Kayabinar, Kayabinar, Önal, Zengin, \& Köse, 2021; Scanlon \& Pennock, 1987). Ergonomics applies to design anything that involve human beings, sports, leisure, workplace, safety, and health of people. Ergonomics is always there where human factor is involved. It's the branch of science that learn about limitations, intentions, and abilities of human beings. It improves homo sapiens interactions with products, environments, and systems (Dugan, Hochstein, Rouziou, \& Britton, 2019; Robertson et al., 2009).

However, Government in underdeveloped countries often perform their major tasks poorly. Public sector structure of Pakistan has been derived from its inheritance; from the British colonial system of eighteenth century. Since it was formed from British India in 1947, it may not perhaps incept its indigenous procedures of management. Likewise, Universities like organization serves the society slightly in a different style with their potential contribution in generating and sharing knowledge (Khan \& Afzal, 2011). Although, universities are deemed as training and research institutions which need to attract, retain, and develop their employees. Similarly, as enlighten in previous research the performance management and mechanism of the universities and the role of faculty members have the principal importance. The strong mechanism of performance assessment for universities that is being utilized for educating their employees is necessary to be up-to-date and reliable to get the genuine results to evaluate and make decision (Sungu, Weng, $\mathrm{Hu}$, Kitule, \& Fang, 2020). Universities are prestigious institutions for countries. The performance of these institutions might be evaluated, whereas the reservations of the stakeholders should be addressed and taken under consideration during the strategic planning (Rashid et al., 2020). It is important that the country's universities improve their world class ranking by attracting and retaining excellent and experienced academicians and support staff (Hassan \& Hashim, 2011; Hassan, 2008). As being the prestigious institutions of the country universities are expected to produce high quality human resources. Training and development of well-qualified human resource depends on the universities' performance (Kim, Youn, \& Lee, 2019).

Furthermore, it is necessary that the education standards must meet with the international standards and quality of education (Ijaz, Irfan, Shahbaz, Awan, \& Sabir, 2011). Although, in world no one can claim of being perfect or remains perfect in every walk of life, individuals' expertise is limited and even limited to specific extent in different fields (Arif, Hassan, \& Ameer, 2014). Whilst the need of improvement remains present for everyone either institution or the individuals at any stage (Seldin, 1980). Rehman (2016) suggests the infrastructural development in Pakistan's educational system through improving the education, of the faculty members working in higher educational institutions. Although, faculty members and their satisfaction from 
job is still unnoticed. Whilst, it has never been taken extensively for the growth, development and productivity of universities (Yasir, Rizwan, Fiza, \& Javed, 2013). The universities are striving for attainment of their goals by participating in world ranking focusing on research and knowledge generation in different segments of life, engineering, sciences and technology (Besharati, Daneshmandi, Zareh, Fakherpour, \& Zoaktafi, 2020; Moretti et al., 2020). Unfortunately, the governance in public sector universities is too wicked to manage basic requirements of the faculty members like furniture and fixture for the comforts of the academic staff. As they have to stay long in their offices and have to deliver lectures and produce research articles. Sometimes they remain busy in extra curriculum activities and administrative assignments (Crawford et al., 2020; Davis et al., 2020; Rashid et al., 2020). Intrinsic motivation can be attained from one's satisfaction from job, it is not astounding that the current study aped slightly a different approach to the job satisfaction for faculty members working in public sector universities on the basis of basic pay scale (BPS). There are different tracks of faculty hiring, we are focusing only on BPS faculty of public sector universities in Pakistan. The chances of greater job embeddings are presumed in that type of appointment. Job embeddedness is closely connected with organizational commitment but not the same. To keep individuals embedded with the job is not an easy task as people change organizations for better opportunities and financial benefits (Hanna, 2014). One's embeddedness with the job and the factors that enhances greater embeddedness with someone's job, might come as a result of satisfaction from workplace and environment (Gao, 2015). The study is carried out to examine the factors that influence and enhance job satisfaction.

\section{Review of Literature:}

The word Gritty came from grit which means hardly small granules, which in turning derived, via Middle English, from an Old English word for Gravel or Sand. Grit is around since $12^{\text {th }}$ century. Grit arrived in American slang with different meaning such as Persistence or Courage in $19^{\text {th }}$ century. It corresponds and suits like Plucky in sense. In new era, gritty is also being used to illustrate a literary style which denoted as rough and coarse. As faculty members working on the basis of BPS facing lots of problems and scarcities such as inappropriate working conditions, lack of infrastructure, no service structure and statues. Nevertheless, stagnant positions, lack of promotions and minimal salaries had created unrest for faculty members (Quaisar, Khulida, \& Tan, 2014). If the faculty members of public sector universities are working and contributing for the international rankings of the universities of Pakistan, they can be said gritty. An objective measure adopted in the study. To sum up the the following hypothesis is presented as:

\section{$H_{1}: \quad$ Job embeddedness has positively significant relationship with job satisfaction}

The mediating effect of job embeddedness have been observed and remained significantly different for both the employees of public and private intuitions (Rhee, Zhao, \& Kim, 2014). This construct is in its infancy stage and the reliability and validity has not been determined to be examined for the current study. This study defines job satisfaction as an inside psychology from a person's own perceptions about his/her own satisfaction from professional life. Ergonomic can be expressed as study of work. The term ergonomic has been derived from the Greek words which are ergo (work) and nomos (laws). In view of its term, it demonstrates that ergonomic is about the investigation of work in connection to the physiological and mental capacities and limitations of individuals. Ergonomics is the applied study of planning and building gadgets or instruments that individuals need so they can utilize these materials with significant level of productivity and safety (Quaisar et al., 2014). Hence, the aim of ergonomics is to fit the task to the worker not to force the person to adapt to the work environment. The cultural differences are prevailing everywhere in all societies, Pakistani culture is complex in nature as we enjoy more while entrapped during work as we face multitasking at work. We have socially astute and perform most tasks with self-efficacy (Ajzen, 1991; Frazier, Tix, \& Barron, 2004; Zafar, Mohsin, Abrar, \& Ghazanfar, 2014). The study suggested the following hypothesis as follow: 
$H_{2}$ : $\quad J o b$ embeddedness mediates the relationship between interruptions at work, multitasking, self-efficacy, social astuteness, and job satisfaction

\section{Ergonomic and job satisfaction}

The study applied two dimensions of Ergonomics (i) Multitasking and (ii) Interruptions at work. The working environment conditions, and employment demands to the abilities of the employees. Basic instances of ergonomic hazard elements are secured in positions that require tedious movements, heavy lifting, clumsy stances of the wrists, hands, back, neck, and shoulders. Vibrations sway pressure, and cold temperatures may add to the danger of ergonomic related damage. In general, there is a need of data in accordance with ergonomic related injury inside the business (Caruana, Ramaseshan, \& Ewing, 1998; Collins \& Mossholder, 2014).

The essential focal point of the field of ergonomics is to decrease injuries, mishaps, and weariness so as to improve work conditions and execution. This objective can hypothetically be practiced by structuring machines, gear and establishments that can be worked securely, precisely, and proficiently by individuals and giving general rules to the specialized conditions and interaction. Ergonomics, as a science, was considered to apply the learning derived from life sciences to work execution (Kelly \& Morse, 2014).

All the ergonomic practices are to safeguard the employees and to protect them from any hazards at workplace. Application of the said practices enhances the satisfaction from job for employees. Keeping in view the early discussion, current study hypotheses as follow:

$H_{3}: \quad$ Interruptions at work has positively significant relationship with job satisfaction

$\mathrm{H}_{4}$ : $\quad$ Multitasking has positively significant relationship with job satisfaction

\section{Ergonomics and Job Embeddedness}

Ergonomics was supported by the military and led at university labs. Wartime endeavors had focused fundamentally on the plan of little hardware while the post war endeavors started concentrating on the structure of whole workstations and huge spaces (Rehman, Ozturk, \& Zhang, 2019).

The workplace, condition can be described as a dynamic socio-physical framework and can be separated from the workplace as a spot, a physical setting, or a hierarchical unit. This can feature the interdependency between the physical frameworks such as innovation, work necessities and exercises. Nevertheless, the social framework individuals, their qualities, desire and needs individuals' connections to associate, work discernments, importance and corporate culture (Rahman, 2016). There are a few examinations that demonstrate the connection between ergonomic situations with employment execution. Works that need high physical interest can indicate how significantly subordinate the activity execution to ergonomic condition. Health and security guidelines are one of the significant elements of work advertise for the strategy producer that requirements consideration. In developed countries broad writing is accessible on repaying wage differentials and factual estimation of damage however lamentably in developing countries just couple of such examinations exists. With regards to Pakistan a couple of studies have been done (Harisur, Howladar, Rahman, \& Uddin, 2018). In fact, there are some different components which have sway on representative execution, for example, acknowledgment and commendation, pay and money related reward however worker's working environment condition is a key determinant of their degree of execution. A superior working environment energizes a worker's degree of inspiration to perform. In fact, poor working environment condition impacts representatives: wellbeing and security, blunder rate, curiosity, joint effort and coordination with different representatives, truancy and social astuteness, to what extent they remain in the job. The impacts of ergonomics on worker execution were broke down by considering various factors, for example, level of ergonomics in Nigerian associations, factors which impede such practices and various strategies embraced by various association for its usage (Kura, Faridahwati, \& Chauhan, 2014). Keeping in view the early ponder the study hypothesized as follow:

$H_{5}$ : Interruptions at work has positively significant relationship with job satisfaction

$H_{6}: \quad$ Multitasking has positively significant relationship with job satisfaction 


\section{Social Astuteness and Job Embeddedness}

The investigation unveiled that numerous variables were affecting the best possible usage of ergonomics rehearses in developing countries like Pakistan which were ignorance, inadequate important contemplated, individual thought, asset confinements, advances changes, correspondence holes and non-coordination between gear originators and workers. A specific perspective on individual-environment relations is one that expect human responses to situations are fixed and perpetual. It is a robotic model and underestimates that presentation of individuals can be estimated and summed up similarly as the exhibition of physical parts of the environment. Nonetheless, it appears that human responses are variable and conflicting; few guidelines or consensuses are to be found. Specifically, it is evident that individuals' responses to natural boosts are influenced by their impression of the social circumstances wherein they get themselves (Safdar, 2012). In the model of representative interactionism, the physical condition is seen not as a free factor that summons human reactions, however as a vehicle for emblematic correspondence over the span of social association.

The emblematic part of ergonomics is probably going to be of specific hugeness when novel types of lighting are considered. Individuals frequently feel compromised by innovation and are suspicious of its roots and potential impacts. This makes them bound to scrutinize the structure the executives' procedure and to look for some contribution in that procedure. Such sentiments will impact the way they respond to and utilize the ergonomics. Plan analysts can't bear to overlook this hierarchical setting: first, it gives a vital aspect for understanding the explanations for clients' appearances and sentiments; and second, through a comprehension of the authoritative setting, designers might have the option to impact it, to build the likelihood that the structure will be acknowledged and adequately use (Saher, Bibi, Farmanullah, \& Abbas, 2014). To close the discussion current study has hypothesizes as:

$H_{7}: \quad$ Social astuteness has positively significant relationship with job embeddedness

\section{Social Astuteness and Job Satisfaction}

Several studies Baldwin et al. (2009); Di-Fabio (1995) and Morse et al. (2001) infer that the immediate impacts of ergonomics have been widely contemplated, bringing about a valuable yet deficient accumulation of information. The most created territories are visual execution, color recognition, and visual hunt. To some degree less created are the connection between visual execution and work execution, the impact of ergonomics on creation of fatigue, and the impact of age (Rashid et al., 2020; Robertson et al., 2009). The indirect impacts of ergonomics have not been concentrated widely and, subsequently, investigation into this zone is at a beginning period of improvement. The main aberrant impacts that are set up are the alteration of conduct that happens considering poor ergonomics, and the impact of ergonomics on hormone balance. Other circuitous impacts, for example, impression, perception, satisfaction, and solace are conceivable, yet the elements that impact their occurrence and the dependability of the impacts stay to be built up (Davis et al., 2020; Franssila, Okkonen, \& Savolainen, 2016; Michelle, Ciriello, \& Garabet, 2013). The connection among ergonomics and laborer fulfillment and execution is yet dependent upon much on uncertain conditions. Given the financial noteworthiness of even little changes in these components, this is irritating; accordingly, it must be helped via cautious research coordinated at remarkable issues. Therefore, to sump, the debate this study hypothesized as follow:

$H_{8}: \quad$ Social astuteness has positively significant relationship with job satisfaction

\section{Self-Efficacy and Job Embeddedness}

Training and development of representatives and occupation fulfillment of workers are two urgent parts for the presentation of representative. study demonstrated positive effect of preparing 
and improvement and occupation fulfillment with representative execution. Training and development will prompt higher occupation fulfillment level in workers, and they will satisfy their obligations with a lot of duty with best performance. Training and improvement are a solid driver driving towards representative execution (Supriyanto, 2013). So, the supervisors should make methodologies to complete or lead productive and viable preparing programs which will build up the aptitudes of representatives at each level. It was discovered that incredible number of under study respondents consented to the way that was more seasoned representatives don't invite changes in their method for working like regardless they utilize the paper and pen for any documentation as opposed to utilizing PCs or workstations (Iqbal, Rehman, Ali, Khan, \& Khan, 2014).

Haines et al. (2004), further examines that logical proof on the impacts of ergonomics on alertness, watchfulness, and state of mind has been gathering throughout the previous 25 years. Scientists find that the everyday and regular rhythms of rest and action can be affected by ergonomics which identified with framework and mindfulness. No less significant are the asserted impacts of ergonomics on mental errands. Ergonomic levels, just as workplace geometry and shading, influence individuals' impression of a space. The impression of a lit space may influence an individual's capacity to perform cerebral assignments and furthermore gadget generation undertakings. Haines et al., (2004) takes note of that exceptionally ongoing examination by Baron and his associates ensnares lighting as a natural prompt for initiating what is named positive effect. Individuals with positive influence are those bound to help other people, volunteer for more work, take huge risks, and see the broad view. Such characteristics can without doubt influence profitability in work environments (Prajogo, 2014). A large portion of the helpful writing about individual -environment frameworks originate from the industrial and occupational fields. By the by, an incredible greater part of this data is pertinent in numerous different settings. Individuals and their physical condition apply common impact, and structure autonomous frameworks. Connections among individuals and physical settings vary, contingent upon whether the unit of investigation is the individual, the relational connections, or the whole association. The three units of examination are interrelated in that people take an interest in relational connections and relational connections are components of organizations. (Lindell, 1994). Boubekri et al., (1991) had examined on connection among personality traits and job embeddedness. He discovered proof that supports the investigation which may reinforce the connection among self-efficacy and job related ergonomic awareness among laborers. In his investigation, he found that the connection among lighting and consciousness of ergonomics isn't huge. Thus, to sum up the debate it is hypothesized as follow:

\section{H9: $\quad$ Self-efficacy has positively significant relationship with job embeddedness}

\section{Self-Efficacy and Job Satisfaction}

As per Wilson (2014), job satisfaction is the framework facilitated by dissects of job embeddedness, states to improve the setup of a system, and people's associations with it, rather than focusing on an individual piece of it. That system can be a curios, office, condition, and building, and work site, gathering. These issues include issues that individuals have as they attempt to adjust to any workplace. They incorporate solace and efficiency, communication, and relational connections among laborers, impacts on nature and obviously, the profitability and adequacy of the institute.

\section{H10: $\quad$ Self-efficacy has positively significant relationship with job embeddedness}

The study hypotheses a total of 10 hypotheses from which nine hypotheses represent direct and one represents the indirect relationship. 


\section{Research Design and Methodology}

This study opted quantitative research design. Similarly, like other quantitative studies this study also depends on the survey questionnaire. The study used self-administrated questionnaire adopted from different authentic sources which has been well tested in Asian context. A Questionnaire containing 21 items was distributed to the respondents directly through online. Data were collected during February to May 2021. A total of 289 faculty members from Islamic Republic of Pakistan's Public Sector Universities participated in this study by their kind response. Self-Efficacy consisting of 03 items, Social Astuteness containing 03 items, Job embeddedness containing 03 items and Job Satisfaction consisting of 03 items has been adopted from Dugan et al. (2018). Whilst two dimensions of Ergonomic: Interruptions at work and multitasking consisting of five and four items respectively has been adopted from Franssila et al. (2016). Most commonly Likert scale is used in different survey research so which is a psychometric scale that commonly used in questionnaires was used in the research. The rating scale from 1 to 7 was used where 1 = "Strongly Disagree", 2 = "Disagree", 3 = "Slightly Disagree", 4= "Neutral", 5 = "Slightly Agree", 6 = "Agree" and 7 = "Strongly Agree".

\section{Results and Analysis}

The following figure 01 represents the model:

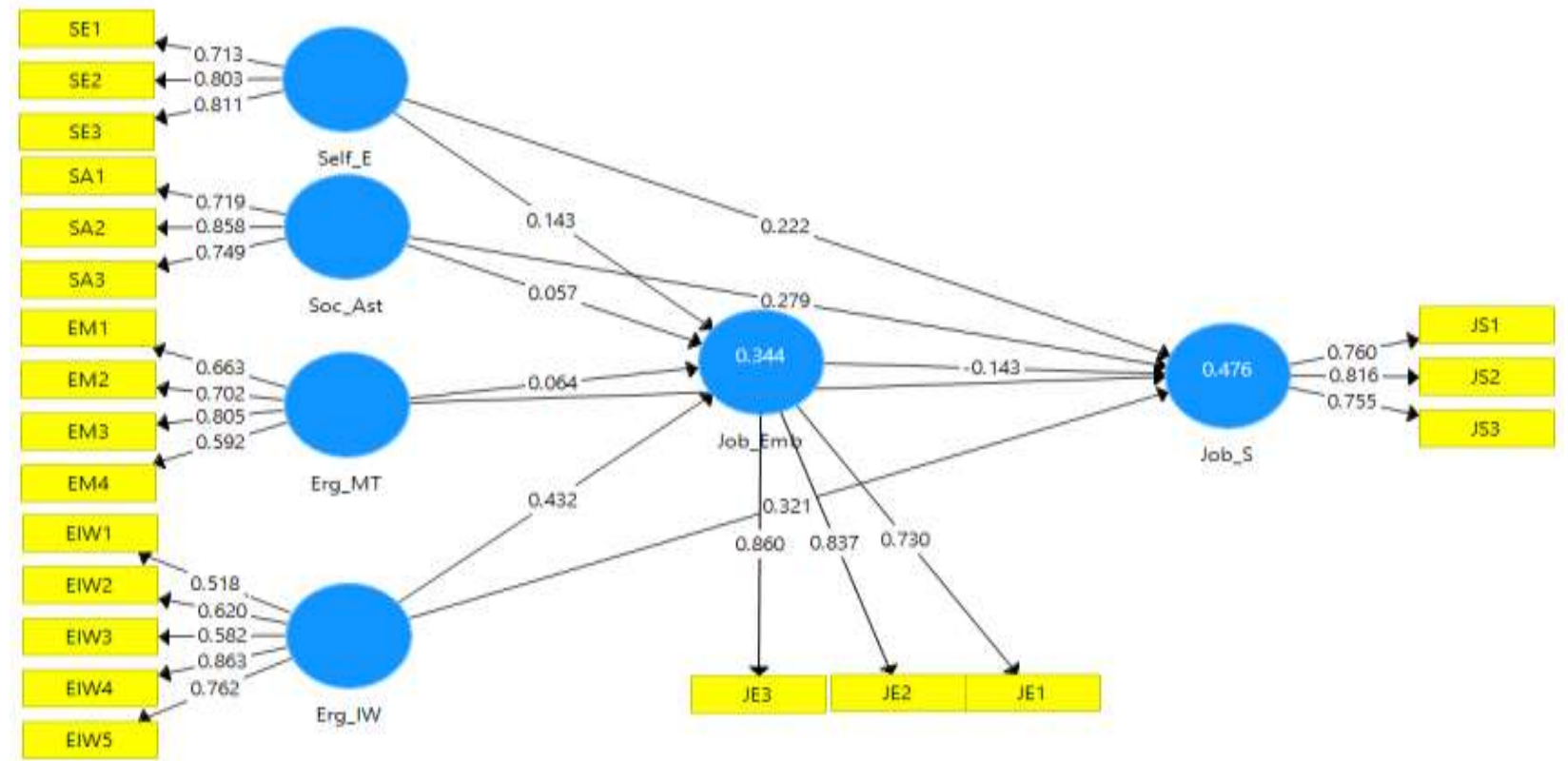

Figure 1: Research Framework

To assess the reliability and validity of the constructs, the study used Cronbach's Alpha, CR, AVE, factor loadings and Fornell-Larcker criterion. Table 1 shows that the values of Cronbach's Alpha as recommended values greater than 0.50 . Results indicates that the values of CR are more than 0.70 . Therefore, the results confirm that the constructs are reliable. Table 1 shows that the values of AVE are more than 0.50.

Table 1: $\quad$ Construct Reliability and Validity

$\begin{array}{lcccc} & \text { Cronbach's Alpha } & \text { rho_A } & \text { Composite Reliability } & \text { Average Variance Extracted (AVE) } \\ \text { Interruptions at Work } & \mathbf{0 . 6 9 5} & \mathbf{0 . 7 1 8} & \mathbf{0 . 8 0 7} & \mathbf{0 . 5 6 4} \\ \text { Job Embeddedness } & \mathbf{0 . 7 5 9} & \mathbf{0 . 8 4 8} & \mathbf{0 . 8 5 1} & \mathbf{0 . 6 5 7} \\ \text { Job Satisfaction } & \mathbf{0 . 6 7 2} & \mathbf{0 . 6 7 3} & \mathbf{0 . 8 2 1} & \mathbf{0 . 6 0 4} \\ \text { Multitasking } & \mathbf{0 . 6 4 0} & \mathbf{0 . 6 3 3} & \mathbf{0 . 7 8 7} & \mathbf{0 . 5 8 3} \\ \text { Self-Efficacy } & \mathbf{0 . 6 8 2} & \mathbf{0 . 7 0 5} & \mathbf{0 . 8 2 0} & \mathbf{0 . 6 0 3} \\ \text { Social Astuteness } & \mathbf{0 . 6 7 2} & \mathbf{0 . 6 9 0} & \mathbf{0 . 8 2 0} & \mathbf{0 . 6 0 5}\end{array}$


Table 2: Outer Loading

\begin{tabular}{|c|c|c|c|c|c|c|}
\hline & $\begin{array}{c}\text { Interruptions at } \\
\text { Work }\end{array}$ & Job Embeddedness & $\begin{array}{c}\text { Job } \\
\text { Satisfaction }\end{array}$ & $\begin{array}{l}\text { Multitaskin } \\
\mathrm{g}\end{array}$ & $\begin{array}{c}\text { Self- } \\
\text { Efficacy }\end{array}$ & $\begin{array}{c}\text { Social } \\
\text { Astuteness }\end{array}$ \\
\hline EIW1 & 0.518 & & & & & \\
\hline EIW2 & 0.620 & & & & & \\
\hline EIW3 & 0.582 & & & & & \\
\hline EIW4 & 0.863 & & & & & \\
\hline EIW5 & 0.762 & & & & & \\
\hline EM1 & & & & 0.663 & & \\
\hline EM2 & & & & 0.702 & & \\
\hline EM3 & & & & 0.805 & & \\
\hline EM4 & & & & 0.592 & & \\
\hline JE1 & & 0.730 & & & & \\
\hline JE2 & & 0.837 & & & & \\
\hline JE3 & & 0.860 & & & & \\
\hline JS1 & & & 0.760 & & & \\
\hline JS2 & & & 0.816 & & & \\
\hline JS3 & & & 0.755 & & & \\
\hline SA1 & & & & & & 0.719 \\
\hline SA2 & & & & & & 0.858 \\
\hline SA3 & & & & & & 0.749 \\
\hline SE1 & & & & & 0.713 & \\
\hline SE2 & & & & & 0.803 & \\
\hline SE3 & & & & & 0.811 & \\
\hline
\end{tabular}

Furthermore, the results shown in table 2 indicate that the outer loading are significant, and loadings are in between 0.518 to 0.863 which are sufficient to satisfy the criteria. The diagonal values in bold are square root of AVE; additionally, the result shows that the square root of AVE is more than the correlation between the variable. That satisfy the criteria for confirming discriminant validity (See Table 3). Thus, the findings of the measurement model of this study confirm the validity and reliability of all constructs.

\begin{tabular}{lcccccc} 
& \multicolumn{2}{c}{ Table 3: Discriminant Validity } & \multicolumn{2}{c}{ Fornell-Larcker Criterion } \\
& $\begin{array}{c}\text { Intruptions at } \\
\text { Work }\end{array}$ & $\begin{array}{c}\text { Job } \\
\text { Embeddedness }\end{array}$ & $\begin{array}{c}\text { Satisfaction } \\
\text { Multitaski }\end{array}$ & $\begin{array}{c}\text { Self } \\
\text { ng }\end{array}$ & $\begin{array}{c}\text { Social } \\
\text { Efficacy }\end{array}$ & $\begin{array}{c}\text { Astuteness } \\
\text { Intruptions at }\end{array}$ \\
$\begin{array}{l}\text { Work } \\
\text { Job }\end{array}$ & $\mathbf{0 . 6 8 1}$ & & & & & \\
Embeddedness & 0.561 & $\mathbf{0 . 8 1 1}$ & & & & \\
Job Satisfaction & 0.559 & 0.281 & $\mathbf{0 . 7 7 7}$ & & & \\
Multitasking & 0.535 & 0.381 & 0.495 & $\mathbf{0 . 6 9 5}$ & & \\
Self-Efficacy & 0.482 & 0.400 & 0.494 & 0.416 & $\mathbf{0 . 7 7 7}$ & \\
Social & 0.464 & 0.345 & 0.540 & 0.475 & 0.398 & $\mathbf{0 . 7 7 8}$ \\
Astuteness & & & & & &
\end{tabular}

The structured model of the study explains the hypothesized relationship of variables. PLS-SEM was used to explain these hypothesized relationships. Table 5 shows model fit indices of the structured model explain that the structured model is a good fit. The values of $\mathrm{R}^{2}$ explained $34.4 \%$ of variance in job embeddedness by and $47.6 \%$ variance in job satisfaction by the 
independent variables (See Table 4).

Job Embeddedness

Table 4: R Square

R Square

0.344

R Square Adjusted

Job Satisfaction

0.476

0.335

0.467

Table 5: Model Fit

Saturated Model

SRMR

d_ULS

d_G

Chi-Square

NFI

rms Theta
0.103

2.465

0.718

1244.878

0.515
Estimated Model

0.103

2.465

0.718

1244.878

0.515

0.196

Furthermore, the path analysis explains that the interruption at work is significantly influencing the job embeddedness and job satisfaction. Therefore, the study accepted the hypotheses. The results show that the job embeddedness is significantly influencing the job satisfaction. The indirect effect of interruption at work on job satisfaction through job embeddedness is also significant (See Table 7). Thus, the relationship between interruption at work and job satisfaction is mediated by the job embeddedness. In addition to that the results in Table 6 shows that the multitasking, self-efficacy, and social astuteness is significantly influencing job satisfaction. However, the results indicate that multitasking, self-efficacy, and social astuteness is not significantly influencing job embeddedness. Moreover, the result of indirect effects shown in Table 7 indicate that the job embeddedness is not significantly mediating the relationship of multitasking, self-efficacy, and social astuteness on job satisfaction.

For further clarification and easy understandings, the figure 02 is presented, in the figure t-values are presented for hypothesis testing. The threshold values, to accept the hypothesis at $95 \%$ level of confidence is 1.96 and above. So the values above 1.96 represents the acceptance of hypothesis.

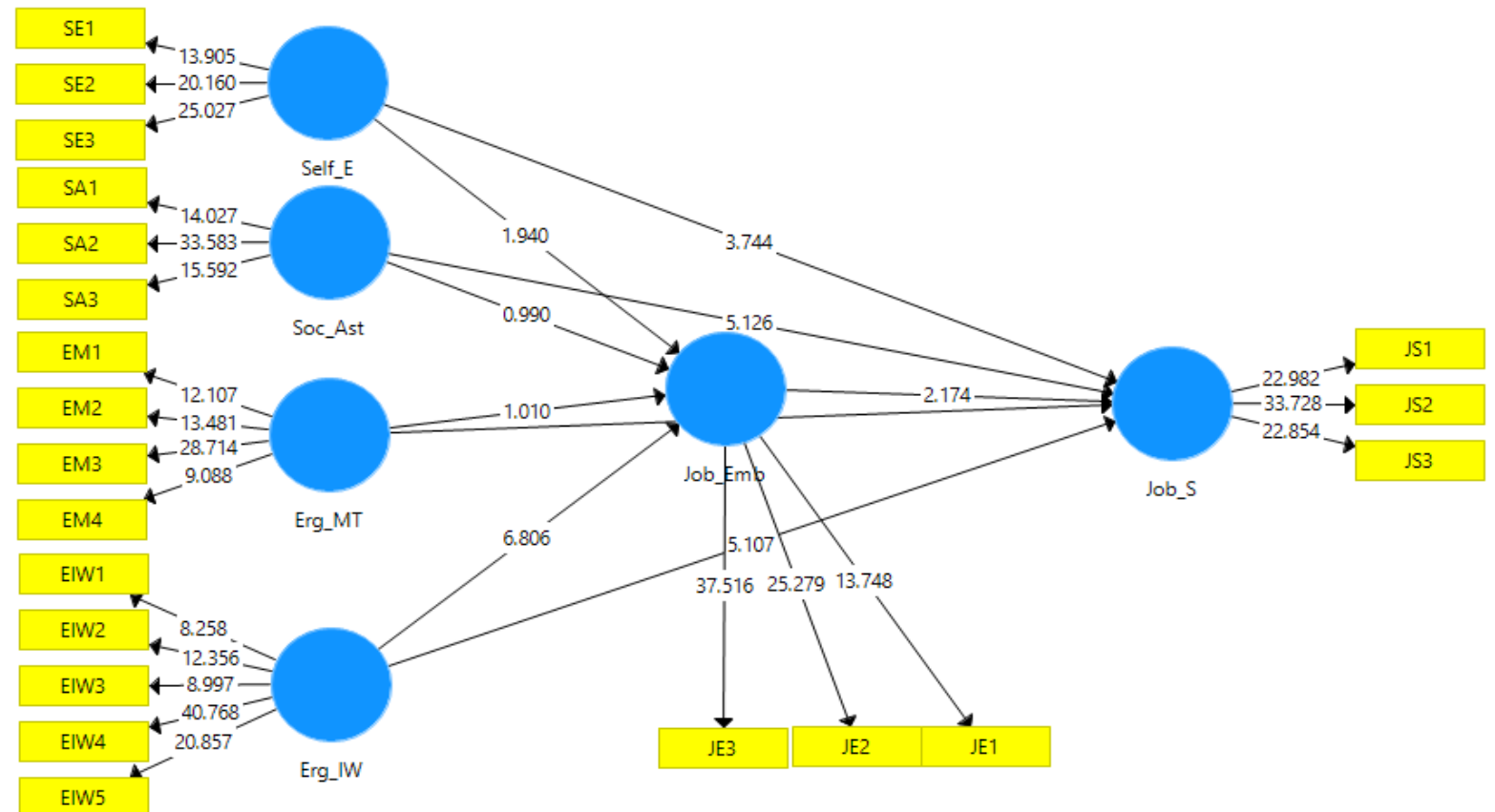


Figure 2: T-statistics

Inline with the figure 02 , table 6 is presented for explanation, nine hypotheses are presented below from which three has been disapproved and six are being accepted as:

Table 6: T-Statistics

\begin{tabular}{|c|c|c|c|c|c|c|}
\hline & 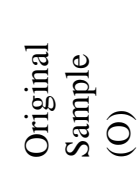 & 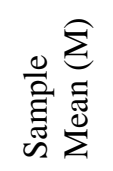 & 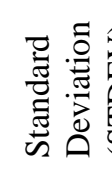 & 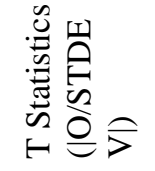 & $\begin{array}{l}\frac{\mathscr{U}}{J} \\
\frac{\pi}{2} \\
2\end{array}$ & 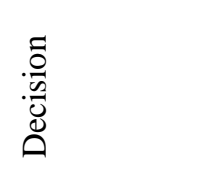 \\
\hline Interruptions at Work -> Job Embeddedness & 0.432 & 0.435 & 0.063 & 6.806 & 0.000 & Accepted \\
\hline Interruptions at Work -> Job Satisfaction & 0.321 & 0.323 & 0.063 & 5.107 & 0.000 & Accepted \\
\hline Job Embeddedness -> Job Satisfaction & -0.143 & -0.148 & 0.066 & 2.174 & $\mathbf{0 . 0 3 0}$ & Accepted \\
\hline Multitasking -> Job Embeddedness & 0.064 & 0.066 & 0.063 & 1.010 & 0.312 & Not Accepted \\
\hline Multitasking -> Job Satisfaction & 0.153 & 0.158 & 0.062 & 2.480 & 0.013 & Accepted \\
\hline Self-Efficacy -> Job Embeddedness & 0.143 & 0.144 & 0.074 & 1.940 & 0.052 & Not Accepted \\
\hline Self-Efficacy -> Job Satisfaction & 0.222 & 0.223 & 0.059 & 3.744 & 0.000 & Accepted \\
\hline Social Astuteness -> Job Embeddedness & 0.057 & 0.054 & 0.058 & 0.990 & 0.322 & Not Accepted \\
\hline Social Astuteness -> Job Satisfaction & 0.279 & 0.280 & 0.054 & 5.126 & 0.000 & Accepted \\
\hline
\end{tabular}

Table 7: Specific Indirect Effect

\begin{tabular}{|c|c|c|c|c|c|}
\hline & 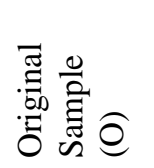 & 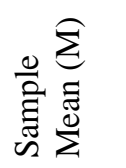 & 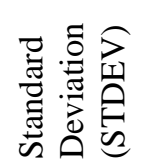 & 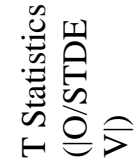 & $\begin{array}{l}\frac{0}{0} \\
\frac{\pi}{\pi} \\
\nu_{0}\end{array}$ \\
\hline Social Astuteness -> Job Embeddedness -> Job Satisfaction & -0.008 & -0.008 & 0.010 & 0.813 & 0.416 \\
\hline Self-Efficacy -> Job Embeddedness -> Job Satisfaction & -0.020 & -0.020 & 0.013 & 1.518 & 0.129 \\
\hline Interruptions at Work $->$ Job Embeddedness $->$ Job Satisfaction & -0.062 & -0.064 & 0.031 & 2.018 & 0.044 \\
\hline Multitasking -> Job Embeddedness -> Job Satisfaction & -0.009 & -0.011 & 0.012 & 0.758 & 0.448 \\
\hline
\end{tabular}

As shown in table 07 the $10^{\text {th }}$ hypothesis is presented, the mediating role of job embeddedness has been established between interruptions at work and job satisfaction and not establish with other attributes. As we are already facing scarcity of infrastructure and facing multitasking, therefore interruption at work come like a cool breath in haphazard situation. Individuals enjoy the interruptions like tea breaks, lunch and gathering of colleagues at workplace. The best time for catharses is interruptions during work, it brings colleagues closer and enhances job embeddedness. In different other cultures people avoid from interruptions while we enjoy interruptions during working hours. And this interruptions are beneficent for employees and organizations too as these interruptions strengthen job embeddedness and increases job satisfaction.

\section{Conclusion and Future recommendations:}

Multitasking is a common prevalence at our work culture and interruptions are common during office hours. Most of the tasks are performed with self-efficacy and independently. The faculty members working on the basis of BPS are equipped with greater job embeddedness and bears higher satisfaction with job. The future researchers are recommended for qualitative research and the construct can be modified with some other type of faculty hiring criteria. 


\section{References:}

Ajzen, I. (1991). The Theory of Planned Behavior. Organizational Behavior and Human Decision Processes.

Arif, M. I., Hassan, A., \& Ameer, H. (2014). HRM Practices in Public and Private Universities of Pakistan. Proceedings of 3rd International Conference on Business Management, (2), 1-14. Retrieved from http://cgr.umt.edu.pk/icobm2013/index.html

Besharati, A., Daneshmandi, H., Zareh, K., Fakherpour, A., \& Zoaktafi, M. (2020). Work-related musculoskeletal problems and associated factors among office workers. International Journal of Occupational Safety and Ergonomics, 26(3), 632-638. https://doi.org/10.1080/10803548.2018.1501238

Caruana, A., Ramaseshan, B., \& Ewing, M. T. (1998). Do universities that are more market orientated perform better? International Journal of Public Sector Management, 11(1), 5570.

Collins, B. J., \& Mossholder, K. W. (2014). Fairness Means More to Some Than Others: Interactional Fairness, Job Embeddedness, and Discretionary Work Behaviors. Journal of Management, 20(10), 1-26. https://doi.org/10.1177/0149206314527132

Crawford, J. O., Berkovic, D., Erwin, J., Copsey, S. M., Davis, A., Giagloglou, E., ... Woolf, A. (2020). Musculoskeletal health in the workplace. Best Practice and Research: Clinical Rheumatology, 34(5), 101558. https://doi.org/10.1016/j.berh.2020.101558

Davis, K. G., Kotowski, S. E., Daniel, D., Gerding, T., Naylor, J., \& Syck, M. (2020). The Home Office: Ergonomic Lessons From the "New Normal." Ergonomics in Design, 28(4), 4-10. https://doi.org/10.1177/1064804620937907

Dugan, R., Hochstein, B., Rouziou, M., \& Britton, B. (2019). Gritting their teeth to close the sale: the positive effect of salesperson grit on job satisfaction and performance. Journal of Personal Selling and Sales Management, 39(1), 81-101. https://doi.org/10.1080/08853134.2018.1489726

Franssila, H., Okkonen, J., \& Savolainen, R. (2016). Developing measures for information ergonomics in knowledge work. Ergonomics, 59(3), 435-448. https://doi.org/10.1080/00140139.2015.1073795

Frazier, P. a., Tix, A. P., \& Barron, K. E. (2004). Testing Moderator and Mediator Effects in Counseling Psychology Research. Journal of Counseling Psychology, 51(1), 115-134. https://doi.org/10.1037/0022-0167.51.1.115

Gao, Y. (2015). Toward a Set of Internationally Applicable Indicators for Measuring University Internationalization Performance. Journal of Studies in International Education, 19(2), 182200. https://doi.org/10.1177/1028315314559030

Hanna, A. L. (2014). The Global Youth Unemployment Crisis. Duke University, Durham, NC.

Harisur, M., Howladar, R., Rahman, S., \& Uddin, A. (2018). Deviant Workplace Behavior and Job Performance: The Moderating Effect of Transformational Leadership. 11(1). https://doi.org/10.22059/ijms.2018.226143.672514

Ijaz, a, Irfan, S. M., Shahbaz, S., Awan, M., \& Sabir, M. (2011). An Empirical Model of Student Satisfaction : Case of Pakistani Public Sector Business Schools. Journal of Quality and Technology Management, 7(2), 91-114.

Iqbal, A., Rehman, K., Ali, A., Khan, I., \& Khan, F. A. (2014). Critical Analysis of the Problems of Education in Pakistan : Possible Solutions. International Journal of Evaluation and Research in Education, 3(2), 79-84. https://doi.org/2252-8822

Kayabinar, E., Kayabinar, B., Önal, B., Zengin, H. Y., \& Köse, N. (2021). The musculoskeletal problems and psychosocial status of teachers giving online education during the COVID-19 pandemic and preventive telerehabilitation for musculoskeletal problems. Work, 68(1), 3343. https://doi.org/10.3233/WOR-203357

Kelly, B., \& Morse, R. (2014). Quaid-i-Azam University ranked among 500 Best Global Universities. Qatar.

Khalid, M., Chaudhry, A. R., \& Ilyas, M. (2014). HRM practices and employee performance in 
public sector organizations in Pakistan: An empirical study. International Journal of Management Sciences and Business Research, 3(2), 69-77.

Khan, M. A., \& Afzal, H. (2011). High level of education builds up strong relationship between organizational culture and organization performance in Pakistan. The International Journal of Human Resource Management, 22(7), 1387-1400.

https://doi.org/10.1080/09585192.2011.561955

Kim, H., Youn, S., \& Lee, D. (2019). The effect of corporate social responsibility reputation on consumer support for cause-related marketing. Total Quality Management and Business Excellence, 30(5-6), 682-707. https://doi.org/10.1080/14783363.2017.1332482

Kura, K. M., Faridahwati, M. S., \& Chauhan, A. (2014). Influence of organisational formal control, group norms, self-regulatory efficacy on workplace deviance in the Nigerian universities: Data screening and preliminary analysis. 7th National Human Resource Management Conference, 1-9. Kedah D.A. Malaysia-06010: SBM_Universiti Utara Malaysia.

Michelle, R. M., Ciriello, V. M., \& Garabet, A. M. (2013). Office ergonomics training and a sitstand workstation: Effects on musculoskeletal and visual symptoms and performance of office workers. Applied Ergonomics, 44(1), 73-85. https://doi.org/10.1016/j.apergo.2012.05.001

Moretti, A., Menna, F., Aulicino, M., Paoletta, M., Liguori, S., \& Iolascon, G. (2020). Characterization of home working population during covid-19 emergency: A cross-sectional analysis. International Journal of Environmental Research and Public Health, 17(17), 1-13. https://doi.org/10.3390/ijerph17176284

Prajogo, D. I. (2014). The strategic fit between innovation strategies and business environment in delivering business performance. International Journal of Production Economics, 171, 241249. https://doi.org/10.1016/j.ijpe.2015.07.037

Quaisar, I. K., Khulida, K. Y., \& Tan, F. (2014). The Effect of Human Capital, Reward System and Career Commitment on Career Success: Mediating Role of Counterproductive Work Behaviour in Higher Education Sector of Pakistan. 7th National Human Resource Management Conference, 14-19.

Rahman, M. M. H. A. A. (2016). Predicting intention to participate in family takaful scheme using Decomposed Theory of Planned Behaviour. International Journal of Social Economics, 43(12), 1-12.

Rashid, H., Mohammadfam, I., Babamiri, M., Soltanian, A. R., Khotanlou, H., \& Sohrabi, M. S. (2020). What do the different ergonomic interventions accomplish in the workplace? A systematic review. International Journal of Occupational Safety and Ergonomics, O(0), 126. https://doi.org/10.1080/10803548.2020.1811521

Rehman, A., Ozturk, I., \& Zhang, D. (2019). The causal connection between CO2 emissions and agricultural productivity in Pakistan: Empirical evidence from an autoregressive distributed lag bounds testing approach. Applied Sciences (Switzerland), 9(8). https://doi.org/10.3390/app9081692

Rhee, J., Zhao, X., \& Kim, C. (2014). Effects of HRM Practices on Chinese Firms' Organizational Performance: The Moderating Effect of CEO Support. Asian Social Science, 10(13), 210-221. https://doi.org/10.5539/ass.v10n13p210

Robertson, M., Amick, B. C., DeRango, K., Rooney, T., Bazzani, L., Harrist, R., \& Moore, A. (2009). The effects of an office ergonomics training and chair intervention on worker knowledge, behavior and musculoskeletal risk. Applied Ergonomics, 40(1), 124-135. https://doi.org/10.1016/j.apergo.2007.12.009

Safdar, R. (2012). Performance measurement and civil services reforms in pakistan : a study of public sector organizations. Far East Research Centre, 6(3), 56-68.

Saher, N., Bibi, S., Farmanullah, S., \& Abbas, S. (2014). Career Success in Pakistan : Human Capital and Social Networking. Middle East Journal of Scientific Research, 19(2), 163-171. https://doi.org/10.5829/idosi.mejsr.2014.19.2.2203 
Scanlon, D. C., \& Pennock, R. (1987). Agronomic competencies: A comparison of their use and perceived importance. Journal of Agronomic Education, 16(1), 16-20. https://doi.org/10.2134/jae1987.0016

Seldin, P. (1980). Successful faculty evaluation programs: A practical to improve faculty performance and promotion tenuredecisions,. Conventry press, Curgers.

Sungu, L. J., Weng, Q., Hu, E., Kitule, J. A., \& Fang, Q. (2020). How Does Organizational Commitment Relate to Job Performance? A Conservation of Resource Perspective. Human Performance, 33(1), 52-69. https://doi.org/10.1080/08959285.2019.1699562

Supriyanto, A. S. (2013). Role of Procedural Justice, Organizational Commitment and Job Satisfaction on job Performance: The Mediating Effects of Organizational Citizenship Behavior. International Journal of Business and Management, 8(15), 57-68. https://doi.org/10.5539/ijbm.v8n15p57

Yasir, S., Rizwan, M. K., Fiza, S., \& Javed, I. (2013). Career Development an Imperative of Job Satisfaction and Career Commitment : Empirical Evidence from Pakistani Employees in Banking Sector. European Journal of Business and Management, 05(21), 108-119.

Zafar, S. S., Mohsin, B., Abrar, M., \& Ghazanfar, F. (2014). Examining the Mediating Role of Employee Career Development in the Relationship between Learning Organization and Organizational Performance. International Journal of Business and Behavioral Sciences, 4(6), 55-69. 